\title{
On a New High-Magnetic Permeability Alloy "Nimalloy" in the Nickel and Manganese System*
}

\author{
By Hakaru Masumoto**, Takeo Kobayashi** \\ and Yūetsu Murakami**
}

\begin{abstract}
After cooling at various rates from $900^{\circ} \mathrm{C}$ or the subsequent heating at various temperatures below the order disorder transformation temperature, the magnetic properties of ferromagnetic nickel-manganese alloys have been measured at room temperature with the ring-form specimens punched out from the plates, and the relation between magnetic permeability and order-disorder transformation of $\mathrm{Ni}_{3} \mathrm{Mn}(23.78 \mathrm{wt} \% \mathrm{Mn})$ has been investigated. It has been found that the initial and maximum permeabilities become larger as the cooling rate decreases or the subsequent heating temperature increases : the initial permeability vs. composition curve shows only one maximum, and the maximum permeability vs. composition curve, two maxima. The alloy containing $21.91 \%$ manganese shows the highest initial permeability of 6860 when heated at $380^{\circ} \mathrm{C}$ for $50 \mathrm{hr}$ after cooling at a rate of $10^{\circ} \mathrm{C} / \mathrm{hr}$ from $900^{\circ} \mathrm{C}$ and the alloy with the composition of $22.00 \%$ manganese attains the highest maximum permeability of 20,400 when heat treated similarly: the former has a magnetic hysteresis loss of 18.3 $\mathrm{erg} / \mathrm{cm}^{3} / \mathrm{cycle}(B \max =2000 \mathrm{G})$, a coercive force of $0.031 \mathrm{Oe}$ and a specific electrical resistivity of $60.7 \mu \Omega-\mathrm{cm}$ at $20^{\circ} \mathrm{C}$. Moreover, these alloys can be forged and rolled more readily than Permalloy and are therefore named "Nimalloy" because they are the alloys of nickel and manganese.
\end{abstract}

(Received November 19, 1966)

This paper was presented at the Spring Meeting of the Japan Institute of Metals, April 5, 1963, Tokyo, Japan. Published originally in Japanese in the Journal of the Japan Institute of Metals, 29 (1965), 228: The 8 th report from the Foundation:
The Research Institute of Electric and Magnetic Alloys Sendai, Japan.

** The Foundation: The Research Institute of Electric and Magnetic Alloys, Sendai, Japan. 


\section{Introduction}

One of the present authors has made, with other collaborators, a study on the relation between magnetic properties and magnetostriction or superlattice formation in ferromagnetic alloys, and found that there is a close relation between them. As a consequence of the study, he discovered a new alloy high in permeability comparable with Sendust $\left(\mathrm{Fe}-\mathrm{Si}-\mathrm{Al}\right.$ alloy) ${ }^{(1)}$ and Alperm ( $\mathrm{Fe}-\mathrm{Al}$ alloy)(2).

Directing attention to the existence of orderdisorder transformation of $\mathrm{Ni}_{3} \mathrm{Mn}$ in nickel-manganese alloys, the authors have recently studied on the relation between degree of order and magnetic properties in the alloys.

A large number of studies(4) (8) have been carried out on the phase diagrams of nickel-manganese alloys since Zemezuzny, Urasow and Rykowskow ${ }^{(3)}$ initiated their work in 1908. As related to the phase diagrams on the nickel-rich side, Kaya and Kussmann ${ }^{(9)}$ were the first to measure in greater detail the variation of the electrical and magnetic properties of nickel alloys containing $15 \sim 40 \%$ manganese after various heat treatments, and explained that a ferromagnetic superlattice $\mathrm{Ni}_{3} \mathrm{Mn}$ would be formed in nickel alloys either by slow cooling from high temperatures or by heating for a long time at temperatures below $500^{\circ} \mathrm{C}$ after rapid cooling. The ordered phase was later comfirmed by means of $\mathrm{X}$ ray and neutron diffraction techniques by Dehlinger and other workers ${ }^{(10) \sim(13)}$. The magnetic transformation points indicated in Fig. $1^{(14)}$ are those obtained by Kaya and Kussmann ${ }^{(9)}$ and also by Köster and Rauscher(15), while the order-disorder transformation temperatures are those derived from thermal analysis and the variation in modulus of elasticity by Köster and Rauscher ${ }^{(5)}$.

The order-disorder transformation temperatures shown

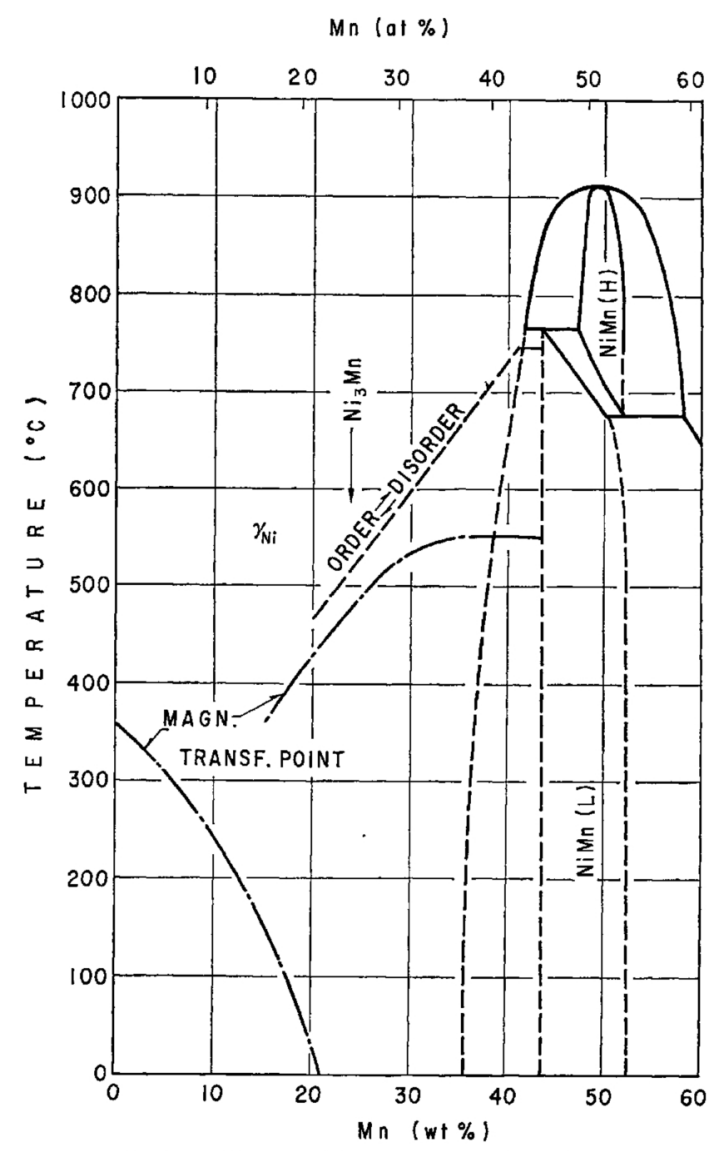

Fig. 1 Equilibrium diagram of Ni-Mn alloys.

Table 1 Results of chemical analysis of metals used.

\begin{tabular}{r|c|c|c|c|c|c|c|c|c}
\hline \hline & $\mathrm{Co}(\%)$ & $\mathrm{Fe}(\%)$ & $\mathrm{Mn}(\%)$ & $\mathrm{Si}(\%)$ & $\mathrm{Cu}(\%)$ & $\mathrm{Pb}(\%)$ & $\mathrm{C}(\%)$ & $\mathrm{P}(\%)$ & $\mathrm{S}(\%)$ \\
\hline Electrolytic Ni & 0.180 & 0.003 & 0.000 & $0.000^{2}$ & $0.001^{8}$ & 0.000 & 0.002 & - & $0.000^{3}$ \\
$\% \mathrm{Mn}$ & - & 0.010 & - & 0.100 & - & - & 0.005 & $\mathrm{Trace}$ & 0.043 \\
\hline
\end{tabular}

(1) H. Masumoto and T. Yamamoto: J. Japan Inst. Metals, 1(1937), 127 ; H.Masumoto: Sci. Rep., Tohoku Imp. Univ., Anniversary (1936), 388.

(2) H. Masumoto and H. Saito: J. Japan Jnst. Metals, 12(1948), 6: Sci. Rep. RITU, A-4 (1952), 321

(3) S. Zemczuzny, G. Urasow and A. Rykowskow: Z. anorg. Chem., 57 (1908), 261.

(4) A. Dourdine: Rev. Mét, 12 (1915), 125 ; 29 (1932), 507, 565

(5) W. Köster and W. Rauscher: Z. Metallk., 39 (1948), 178.

(6) B. R. Coles and W. Hume-Rothery: J. Inst. Metals, 80 (1951), 85.

(7) N. N. Kurnakov and M. Ya. Troneva: Doklady Akad. Nauk S.S.S.R., $68(1949), 73$.

(8) V.N. Eremenko and T.D. Shtepa: Ukrain. Khem. Zhur., 18 (1952), 219.

(9) S. Kaya and A. Kussmann: Z. Physik, 72 (1931), 293.

(10) U. Dehlinger : see A. Kussmann, B.Scharnow and W. Steinhaus, Festschrift der Heraeus Vacuumschmelze, Hanau, (1933), 319 .

(11) C. G. Shull and S. Siegel : Phys. Rev., 75 (1949), 1008.

(12) B. L. Averbach: J. Appl. Phys., 22 (1951), 1088.

(13) C. G. Shull and M. K.Wilkinson: Phys. Rev., 97 (1955), 304.

(14) M. Hansen : Constitution of Binary Alloys. Metallurgy and Metallurgical Engineering Series, 2nd Edition (1958).

(15) M. J. Marcinkowski and N. Brown: J. Appl. Phys., 32 (1961), 375. in Fig. 1 concerns with the long-range order. Recently, Marcinkowski and other workers(15)(16) have also made clear that there exists the short-range order in nickelmanganese alloys at relatively high temperatures.

As for the magnetic permeability, Gumlich, Steinhaus, Kussmann and Scharnow ${ }^{(17)}$ obtained an initial permeability of 2,380 and a coercive force of 0.12 Oe in a nickel alloy containing $17 \%$ manganese by slow cooling from $900^{\circ} \mathrm{C}$, while the maximum permeability obtained by Jaffee ${ }^{(18)}$ was 5,300 in a $\mathrm{Ni}_{3} \mathrm{Mn}$ alloy heated at $380^{\circ} \mathrm{C}$ for a long time. And no detailed and systematic studies on the relation between superlattice $\mathrm{Ni}_{3} \mathrm{Mn}$ and magnetic permeability have heretofore been carried out. In view of this, the authors have investigated the relation of magnetic properties vs. cooling rate for the alloys within the range of the $\mathrm{Ni}_{3} \mathrm{Mn}$ phase as reported in the

(16) M. J. Marcinkowski and R. M. Poliak : Phil. Mag., 8(1963), 1023.

(17) E. Gumlich, W. Steinhaus, A. Kussmann and B. Scharnow : Elektr. Nachr-Techn., 5 (1928), 83.

(18) R. I. Jaffee: J. Appl. Phys., 19(1948), 867. 
following.

\section{Samples and Experimental Methods}

Electrolytic nickel and electrolytic manganese were used as materials, with the chemical composition shown in Table 1.

For sample preparation ( $700 \mathrm{~g}$ in total weight), nickel was placed in an alumina crucible and its surface was covered with an appropriate flux to prevent oxidation, and melted by a high frequency electric induction furnace. Then, manganese was added to the melt and mixed thoroughly to make a homogeneous alloy. It was cast into an iron mould $30 \mathrm{~mm}$ in square and $90 \mathrm{~mm}$ in length, and the ingot was forged to an about $80 \mathrm{~mm}$ thick plate. Further, the plate was rolled at $1000^{\circ} \mathrm{C}$ to a thickness of about $1 \mathrm{~mm}$ and then cold-rolled to a thin plate of $0.3 \mathrm{~mm}$-thickness, from which a ring-form specimen $35 \mathrm{~mm}$ in inner diameter and $46 \mathrm{~mm}$ in outer diameter was punched out. Finally, five sheets of the ring-form plates thus prepared were laminated to become equiangular with each other in the rolling direction. After heating in vacuum at $900^{\circ} \mathrm{C}$ for $1 \mathrm{hr}$, they were cooled to room temperature at various rates or further heated at various temperatures within the range of orderdisorder transformation. The specimens within the composition range of $0 \sim 35.56 \%$ manganese numbered 53 kinds. The magnetizing coil and search coil were coiled round the five laminated plates and the magnetic properties were measured by the ballistic method.

On the other hand, a part of the above-mentioned ingot was cut out and made into a cylindrical rod of about 5 mm diameter. The diameter of the rod was then reduced to about $2 \mathrm{~mm}$ by using a swaging hammer at room temperature, from which a rod about $100 \mathrm{~mm}$ in length was cut out. The rod heat-treated in the same way as for the above-mentioned ring-form plate was used for the measurement of magnetization at an effective field of $900 \mathrm{Oe}$ and of electric resistance. The electric resistance was measured by a potentiometer method, and its mean temperature coefficient was obtained over $0^{\circ} \sim$ $40^{\circ} \mathrm{C}$.

\section{Experimental Results and Considerations}

The results of measurements are given in Figs. $2 \sim 5$. In Figs. 2 and 3 are shown the observed values of the initial permeability $\mu_{0}$ and the maximum permeability $\mu_{m}$ in nickel-manganese alloys which were heated at $900^{\circ} \mathrm{C}$ for $\mathrm{I} \mathrm{hr}$ and then cooled to room temperature at six different rates of $170^{\circ} \mathrm{C} / \mathrm{sec}, 240^{\circ} \mathrm{C} / \mathrm{hr}, 100^{\circ} \mathrm{C} / \mathrm{hr}, 10^{\circ}$ $\mathrm{C} / \mathrm{hr}, 5^{\circ} \mathrm{C} / \mathrm{hr}$ and $3^{\circ} \mathrm{C} / \mathrm{hr}$.

As can be seen from the figures, $\mu_{0}$ would gradually increase with increasing manganese content and then decrease after passing through a maximum. The maxmum is considerably small at the cooling rate of $170^{\circ} \mathrm{C} / \mathrm{sec}$, but it increases rapidly with decreasing cooling rate and the position shifts to the manganese-rich side. When the cooling rate becomes extremely small, however, the maximum decreases again. The maximum value of $\mu_{0}$ is 5,090 at the cooling rate of $5^{\circ} \mathrm{C} / \mathrm{hr}$ with the com- position of $21.80 \%$ manganese. With the exception of a case at the cooling rate of $170^{\circ} \mathrm{C} / \mathrm{sec}$, the maximum permeability vs. concentration curves has two maxima ; Either of the maxima increases gradually with decreasing cooling rate and the position of the first maximum shifts

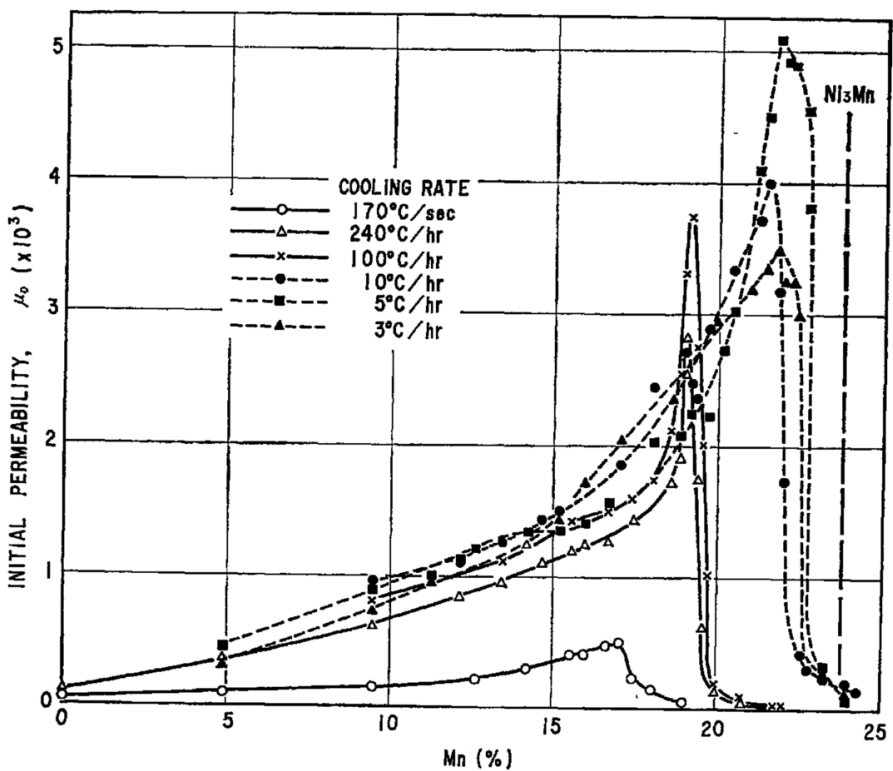

Fig. 2 Initial permeabilities of $\mathrm{Ni}-\mathrm{Mn}$ alloys cooled to room temperature at various rates after heating at $900^{\circ} \mathrm{C}$ for $1 \mathrm{hr}$.

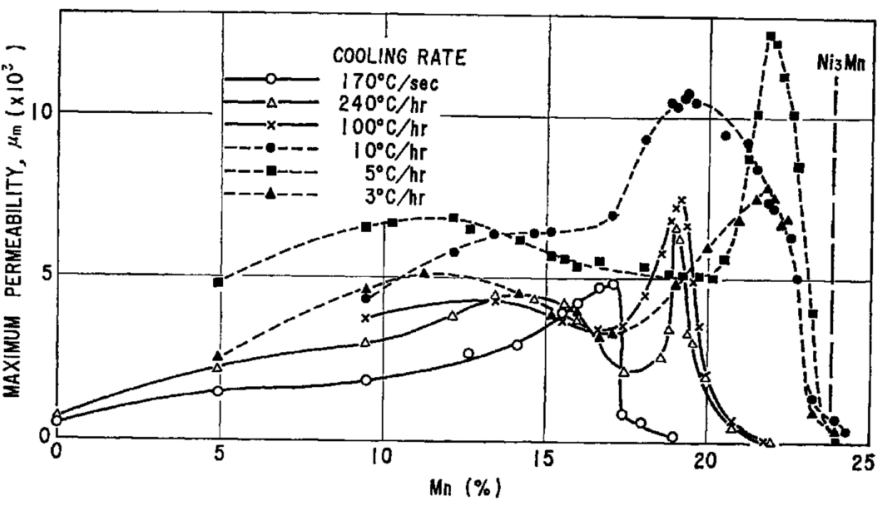

Fig. 3 Maximum permeabilities of $\mathrm{Ni}-\mathrm{Mn}$ alloys cooled to room temperature at various rates after heating at $900^{\circ} \mathrm{C}$ for $1 \mathrm{hr}$.

to the manganese-low side and that of the second maximum to the manganese-rich side. However, even in this case, the two maxima decrease again as the cooling rate becomes extremely small in a way similar to the initial permeability. The maximum value of $\mu_{m}$ is 12,490 at the cooling rate of $5^{\circ} \mathrm{C} / \mathrm{hr}$ with the composition of $21.80 \%$ manganese.

Next, Fig. 4 shows the relation between the intrinsic magnetic induction $4 \pi I$ and the manganese content at an effective magnetic field of $900 \mathrm{Oe}$ for the rod specimens mentioned above. The values of $4 \pi I$ is known to increase with increasing manganese content when cooled rapidly at the rate of $170^{\circ} \mathrm{C} / \mathrm{sec}$ and to attain a maximum at about $8 \%$ manganese, but thereafter it gradually decreases initially and then rapidly. And it becomes nonmagnetic at manganese contents of more than about $23 \%$ manganese. At the slower cooling rate, $4 \pi I$ indicates a gradual decrease up to about $22 \%$ manganese with increasing manganese content. At more than about $22 \%$ manganese, the second maximum appears at about 
$24 \%$ manganese $\left(\mathrm{Ni}_{3} \mathrm{Mn}\right)$ and at the slow cooling rates of $10^{\circ} \mathrm{C} / \mathrm{hr}, 5^{\circ} \mathrm{C} / \mathrm{hr}$ and $3^{\circ} \mathrm{C} / \mathrm{hr}$, among which the trend is most remarkable at $3^{\circ} \mathrm{C} / \mathrm{hr}$ where the maximum value reaches $5,045 \mathrm{G}$. As is evident from the results of other workers, this can be attributed to the advance of super-

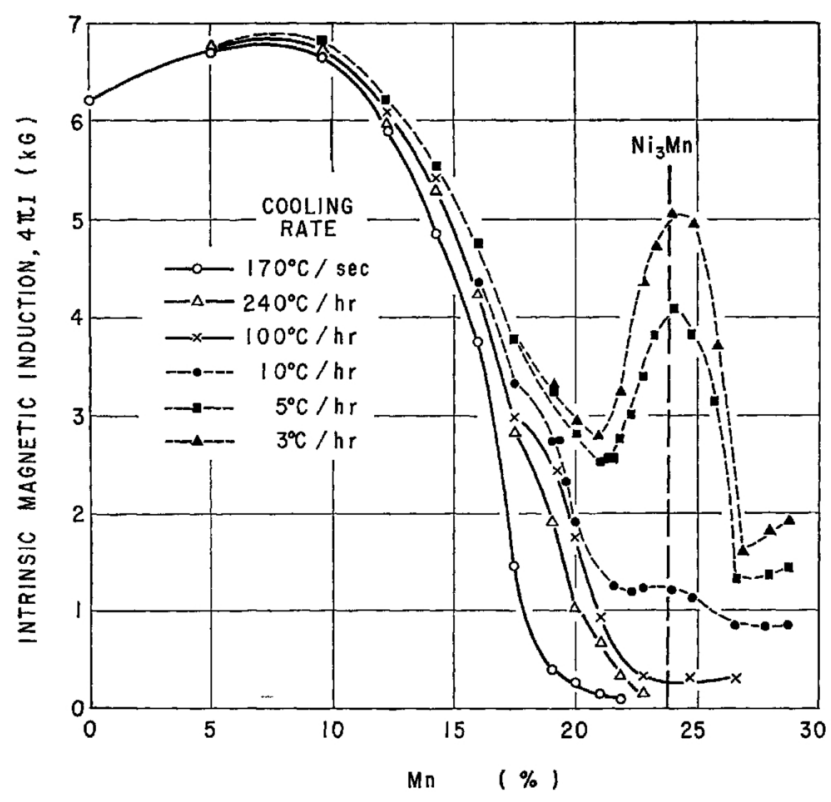

Fig. 4 Intrinsic magnetic induction at an effective field of 900 $\mathrm{Oe}$ in Ni-Mn alloys cooled to room temperature at various rates after heating at $900^{\circ} \mathrm{C}$ for $1 \mathrm{hr}$.

lattice formation with decreasing cooling rate.

The above-cited specimens cooled at the various rates were further heated at varying temperatures below the order-disorder transformation temperature, and the values of $\mu_{0}$ and $\mu_{m}$ were measured at room temperature. Among these specimens, the values of $\mu_{0}$ and $\mu_{m}$ against the manganese composition in those heated at $300^{\circ}$, $350^{\circ}, 380^{\circ}, 400^{\circ}, 450^{\circ}$ and $480^{\circ} \mathrm{C}$ for $50 \mathrm{hr}$ after cooling at the rate of $10^{\circ} \mathrm{C} / \mathrm{hr}$ are shown in Figs. 5 and

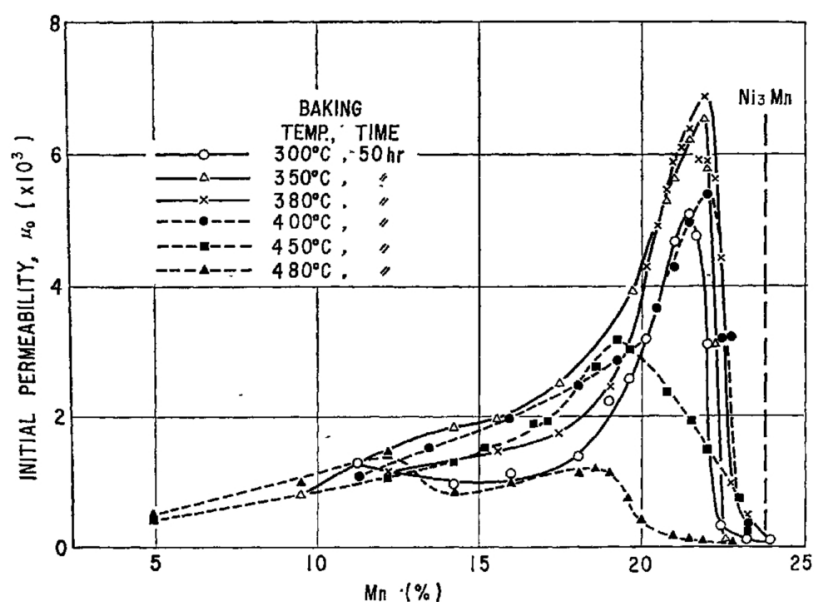

Fig. 5 Initial permeabilities of $\mathrm{Ni}-\mathrm{Mn}$ alloys heated at various temperatures for $50 \mathrm{hr}$ after cooling at a rate of $10^{\circ} \mathrm{C} / \mathrm{hr}$ from $900^{\circ} \mathrm{C}$

6. In general the $\mu_{0}$ and $\mu_{m}$ vs. composition curves closely resemble those obtaind by changing the above cooling rates. In other words, the raising of the heating temperature and the lowering of the cooling rate reveal a similar effect to each other, which is considered a natural phenomenon in alloys with the order-disorder transformation. The highest values of $\mu_{0}$ and $\mu_{m}$ are 6,860 in a $21.91 \%$ manganese alloy heated at $380^{\circ} \mathrm{C}$ for $50 . \mathrm{hr}$ and 20,400 in a $22.00 \%$ manganese alloy similarly heat-treated, respectively, both values being considerably

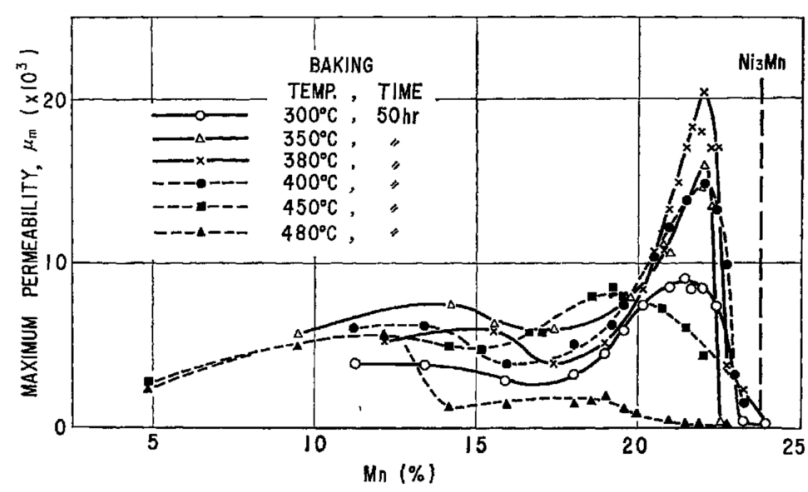

Fig. 6 Maximum permeabilities of Ni-Mn alloys heated at various temperatures for $50 \mathrm{hr}$ after cooling at a rate of $10^{\circ} \mathrm{C} / \mathrm{hr}$ from $900^{\circ} \mathrm{C}$.

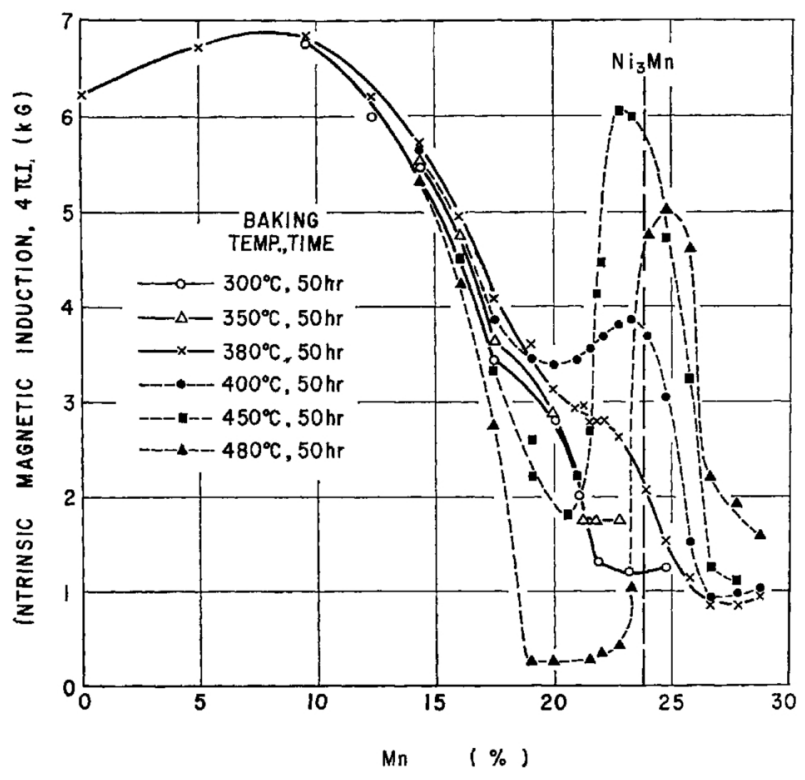

Fig. 7 Intrinsic magnetic induction at an effective field of $900 \mathrm{Oe}$ in Ni-Mn alloys baked at various temperatures for $50 \mathrm{hr}$ after cooling at a rate of $10^{\circ} \mathrm{C} / \mathrm{hr}$ from $900^{\circ} \mathrm{C}$.

high compared with those in the alloys subjected only to cooling.

Fig. 7 shows the relation between $4 \pi I$ and composition measured at the effective field of $900 \mathrm{Oe}$ for the specimens which were further heated at the various temperatures below the order-disorder transformation temperature after cooling at $10^{\circ} \mathrm{C} / \mathrm{hr}$. This $4 \pi I$ vs. concentration curve is closely analogous with that in Fig. 4 obtained from the specimen only subjected to cooling at the various rates. This is also considered to be a natural consequence in so far as the alloys have the order-disorder transformation, in the same way as for $\mu_{0}$ and $\mu_{m \text {. }}$ In this case, the maximum value of $4 \pi I$ is 6,054 in a 22.72 $\%$ manganese alloy heated at $450^{\circ} \mathrm{C}$ for $50 \mathrm{hr}$, showing a fairly high value compared with $5,045 \mathrm{~g}$ in a $24 \%$ manganese alloy cooled at the rate of $3^{\circ} \mathrm{C} / \mathrm{hr}$. Moreover, the reason why $4 \pi I$ is small in the case of heating at 
$480^{\circ} \mathrm{C}$ than at $450^{\circ} \mathrm{C}$ might be attributed to the partial decrease in degree of the long-range order due to the fact that the temperature of $480^{\circ} \mathrm{C}$ lies in the proximity of the order-disorder transformation temperature.

Comparison of Figs. $2 \sim 7$ shows that the maximum hysteresis curve might be attributed to the fact that the alloy consists of a mixture of long-range and short-range ordered phases.

In short, by appropriate heat treatment, the ferromagnetic nickel-manganese alloys under study give rise

Table 2 Magnetic and electric properties of typical Ni-Mn alloys variously heat-treated.

\begin{tabular}{|c|c|c|c|c|c|c|c|c|c|c|c|c|c|}
\hline \multirow{2}{*}{$\begin{array}{l}\text { Alloy } \\
\text { No. }\end{array}$} & \multirow{2}{*}{$\underset{(\%)}{\mathrm{Mn}}$} & \multirow{2}{*}{$\begin{array}{l}\text { Cooling } \\
\text { rate } \\
\left({ }^{\circ} \mathrm{C} / \mathrm{hr}\right)\end{array}$} & \multirow{2}{*}{$\begin{array}{c}\text { Baking } \\
\begin{array}{c}\text { Temperature, } \\
\text { time }\end{array} \\
\end{array}$} & \multirow[b]{2}{*}{$\mu_{0}$} & \multirow{2}{*}{$\mu_{m}$} & \multirow{2}{*}{$\begin{array}{l}\boldsymbol{B}(\mathbf{G}) \\
\text { for } \mu_{m}\end{array}$} & $\begin{array}{l}\text { Wh (erg/ } \\
\left.\mathrm{cm}^{3} / \text { cycle }\right)\end{array}$ & $B r(G)$ & $\mathrm{Hc}(\mathrm{Oe})$ & \multirow{2}{*}{$\begin{array}{c}4 \pi I(\mathrm{G}) \\
H=900 \mathrm{Oe}\end{array}$} & \multirow{2}{*}{$\begin{array}{c}\sigma \\
\left(\mu \Omega_{-\mathrm{cm}}\right. \\
\left.20^{\circ} \mathrm{C}\right)\end{array}$} & \multirow{2}{*}{$\begin{array}{c}\alpha \\
\left(\times 10^{-3}\right. \\
\left.0^{\circ} \sim 10^{\circ} \mathrm{C}\right)^{\prime}\end{array}$} & \multirow{2}{*}{$\begin{array}{l}\text { Density } \\
\left(\mathrm{g} / \mathrm{cm}^{3}\right)\end{array}$} \\
\hline & & & & & & & \multicolumn{3}{|c|}{ for $B_{m}=2000 G$} & & & & \\
\hline 5 & 12.13 & 5 & 一 & 1130 & 6830 & $\mathrm{~L}, 24 \mathrm{~L}$ & 83.9 & $165 \overline{5}$ & 0.130 & 6233 & 31.9 & 2.02 & 8.58 \\
\hline 20 & 19.00 & 210 & 一 & 2310 & 6593 & 163 & $8.5^{k}$ & $410^{\mathrm{k}}$ & $0.030^{*}$ & 1910 & 53.3 & 1.38 & - \\
\hline 21 & 19.12 & 100 & - & $349 \mathrm{~J}$ & $745^{3}$ & 231 & 111.8 & 611 & 0.030 & 2430 & 53.1 & 1.38 & 8.44 \\
\hline 22 & 19.21 & 10 & $45 J^{\circ} \mathrm{C}, 50 \mathrm{hr}$ & 3183 & 8480 & $2 L 0$ & 30.8 & 667 & 0.051 & 2210 & 53.1 & 1.38 & - \\
\hline 23 & 19.33 & 10 & - & 2333 & 10330 & 433 & 33.8 & 915 & 0.042 & 2740 & 53.3 & 1.34 & 一 \\
\hline 32 & 21.47 & 10 & - & 4210 & 8100 & 148 & $4.2^{*}$ & $140^{k}$ & $0.020 *$ & 1256 & 60.1 & 0.68 & - \\
\hline 8 & " & 10 & $300^{\circ} \mathrm{C}, 50 \mathrm{hr}$ & 5093 & 9100 & 630 & $9.0^{*}$ & $337 *$ & $0.025 *$ & - & 59.8 & 0.72 & - \\
\hline 35 & 21.80 & 5 & - & 5093 & 12190 & 626 & 18.5 & 876 & 0.027 & 2760 & 60.5 & 0.94 & $8 \cdot 42$ \\
\hline " & " & 3 & - & 3500 & 7800 & 2082 & 24.5 & 700 & 0.058 & 3231 & 57.8 & 0.92 & - \\
\hline 36 & 21.91 & 10 & $35 \mathrm{~J}^{\circ} \mathrm{C}, 50 \mathrm{hr}$ & 6520 & 14670 & 908 & $10.6^{*}$ & $347^{*}$ & $0.034 *$ & 1760 & 61.2 & 0.99 & 一 \\
\hline " & " & 10 & $380^{\circ} \mathrm{C}, 50 \mathrm{hr}$ & 68000 & 18030 & 891 & 18.3 & $9 \overrightarrow{\mathbf{s}} 4$ & 0.031 & 2790 & 60.7 & 0.93 & - \\
\hline 37 & 22.00 & 10 & $380^{\circ} \mathrm{C}, 50 \mathrm{hr}$ & 5880 & 20100 & 908 & 19.3 & 1052 & 0.027 & 2804 & 60.7 & 0.93 & 8.40 \\
\hline " & $"$ & 10 & $400^{\circ} \mathrm{C}, 50 \mathrm{hr}$ & 5380 & 14700 & 960 & 20.4 & 1075 & 0.030 & 36 & 59.1 & 1.02 & - \\
\hline 43 & 23.24 & 5 & - & 330 & 4010 & - & 2405.0 & 1512 & 3.570 & 3813 & 58.2 & 1.20 & - \\
\hline
\end{tabular}

* For $B_{\max }=1,000 \mathrm{G}$

permeabilities fall into the composition range of less than about $22 \%$ manganese, where the maximum value of permeability is inconsistent with $\mathrm{Ni}_{3} \mathrm{Mn}$ which corresponds to the maximum value of $4 \pi I$ and the permeability itself is extremely small at the $\mathrm{Ni}_{3} \mathrm{Mn}$ composition. This indicates the relation between permeability and orderdisorder transformation in which the permeability decreases all the more when the degree of order increases considerably. The phenomenon bears a close resemblance to the cases of Permalloy $(\mathrm{Fe}-\mathrm{Ni} \text { alloy })^{(19)}$, Sendust $(\mathrm{Fe}-$ $\mathrm{Si}-\mathrm{Al}$ alloy $)^{(1)}$ and Alperm $(\mathrm{Fe}-\mathrm{Al}$ alloy)(2).

Typical magnetic properties of nickel-manganese alloys in the present experiments are listed in Table 2, where $W h$ is the hysteresis loss $\left(B_{\max }=2,000 \mathrm{G}\right)$ and considerably small in value, $\sigma$ the specific electrical resistivity, and $\alpha$ its temperature coefficient. The fact that the value of $\sigma$ is fairly large is advantageous as a high-permeability alloy.

In Fig. 8 are shown magnetization and hysteresis curves

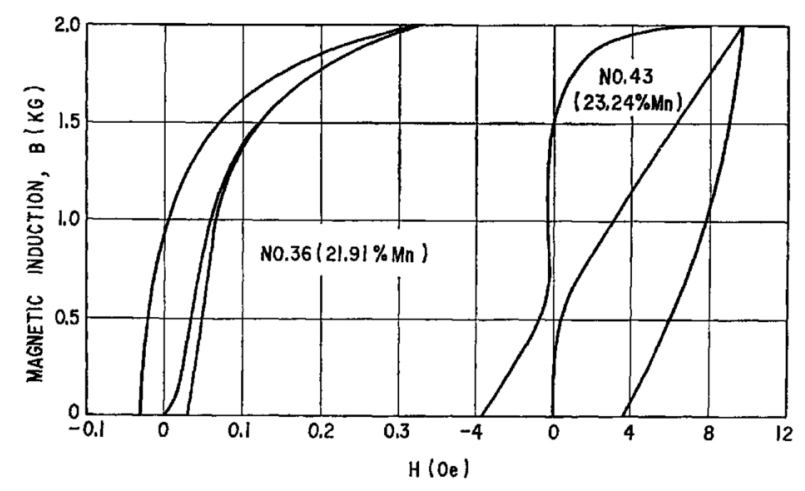

Fig. 8 Hysteresis curves obtained at the maximum induction of $2,000 \mathrm{G}$ in No.36 and No. 43 alloys.

for No. 36 alloy which has the highest initial permeability and is small in hysteresis loss and for No. 43 alloy which is high in coercive force but is the Perminvar type. The cause of formation of this Perminvar-type

(19) G. W. Elmen : J. Franklin Inst., 207 (1929), 582. to high permeability and in addition can more readily $b$. forged and rolled either at room temperature or at high temperatures than commercial Permalloy alloys. The authors, therefore, named these alloys "Nimalloy" because they are the alloys of nickel and manganese.

\section{Summary}

Specimens punched out in a ring form were prepared from 53 kinds of ferromagnetic nickel-manganese alloys containing $0 \sim 35.56 \%$ manganese. After heating at $900^{\circ} \mathrm{C}$ for $1 \mathrm{hr}$, the specimens were cooled to room temperature at various rates or further heated at different temperatures below the order-disorder transformation temperature. The magnetic properties, and electric resistance and its temperature coefficient of the specimens were measured at room temperature, with the results summarized as follows :

(1) The initial permeability becomes larger gradually with increasing manganese content and then decreases rapidly after passing through a maximum. The maximum shows a rapid increase with decreasing cooling rate or with rising heating temperature below the order-disorder transformation temperature, and then decreases after passing through a maximum. The highest value of the initial permeability is 5,090 at a cooling rate of $5^{\circ} \mathrm{C} / \mathrm{hr}$ with $21.80 \%$ manganese when cooled from $900^{\circ} \mathrm{C}$. When heated at various temperatures for different times after cooling at the rate of $10^{\circ} \mathrm{C} / \mathrm{hr}$ and heated at $380^{\circ} \mathrm{C}$ for $50 \mathrm{hr}$, the value is 6,860 .

(2) The maximum permeability vs. concentration curve has in general two maxima, either of which increases gradually with decreasing cooling rate or with raising heating temperature until it attains a maximum and then decreases. The maximum value is 12,490 in the $21.80 \%$ manganese alloy cooled from $900^{\circ} \mathrm{C}$ at $5^{\circ} \mathrm{C} /$ $\mathrm{hr}$ and when heated at a variety of temperature for different times, it is 20,400 in the $22.00 \%$ manganese alloy heated at $380^{\circ} \mathrm{C}$ for $50 \mathrm{hr}$. .

(3) The intrinsic magnetic induction at an effective 
field of 900 Oe increases with decreasing cooling rate or increasing heating temperature, and the rate of increase is greater with increasing manganese content. Moreover, the value indicates a maximum at about $8 \%$ manganese and give rise to a second maximum at about $24 \%$ manganese $\left(\mathrm{Ni}_{3} \mathrm{Mn}\right)$ only by slow cooling or. heating at higher temperatures below the order-disorder transformation temperature. The second maximum reaches 6,054 when heated at $450^{\circ} \mathrm{C}$ for $50 \mathrm{hr}$ after cooling at $10^{\circ} \mathrm{C} / \mathrm{hr}$.

(4) The minimum values of the hysteresis loss and the coercive force against a maximum induction of $2,000 \mathrm{G}$ are as low as $18.3 \mathrm{erg} / \mathrm{cm}^{3} / \mathrm{cycle}$ in the $21.91 \% \mathrm{man}$ ganese alloy and $0.027 \mathrm{Oe}$ in the $21.80 \%$ manganese alloy.

(5) The specific electrical resistivity of the $21.91 \%$ manganese alloy which shows excellent magnetic properties when heated at $380^{\circ} \mathrm{C}$ for $50 \mathrm{hr}$ after slow cooling from $900^{\circ} \mathrm{C}$ at $10^{\circ} \mathrm{C} / \mathrm{hr}$ has a high value of $60.7 \mu \Omega$-cm $\left(20^{\circ} \mathrm{C}\right)$ and its temperature coefficient is $0.93 \times 10^{-3}\left(0^{\circ}\right.$ $\left.\sim 40^{\circ} \mathrm{C}\right)$.

(6) These nickel-manganese alloys are not only distinguished in magnetic properties but also can be more readily forged and rolled than Permalloy, which are named "Nimalloy".

\section{Acknowledgments}

The valuable advice of Prof. $H$. Saito of Tohoku University and the cooperation of Messrs. T. Öizumi, N. Nakamura and M. Hinai in the sample preparation and measurements are gratefully acknowledged. 